\title{
Knowledge Production and Learning for Sustainable Landscapes: Forewords by the Researchers and Stakeholders
}

\author{
Per Angelstam, Marine Elbakidze, Robert Axelsson, \\ Niels Elers Koch, Tatiana I. Tyupenko, \\ Alexandr N. Mariev, Lennart Myhrman
}

\begin{abstract}
This special issue of AMBIO presents a new approach to sustainability science that goes beyond interdisciplinary research. Using coupled natural and human systems, or landscapes, as multiple case studies in Europe's East and West knowledge production and learning toward transdisciplinary research was applied in Sweden, countries in Central and Eastern Europe, and Russia. First, the research group Forest-Landscape-Society summarizes the research program (2005-2012) behind this special issue of AMBIO and its development to participate in transdisciplinary research. Second, stakeholders at multiple levels provide their views on the new approach presented and reported.
\end{abstract}

Keywords Sustainability science - Transdisciplinary · Ecosystem services $\cdot$ Natural experiment $\cdot$ Europe · Russia

\section{INTRODUCTION}

Landscapes deliver goods, functions, and values on which human welfare and quality of life are built. The term ecosystem services capture this, and it was developed to communicate nature as a fixed stock of natural capital that can sustain a limited flow of services (Norgaard 2010). However, given the diverse and often conflicting policy visions in multiple natural resource sectors and the fact that sustainable development is a multi-stakeholder social learning process at local, regional, national, and international levels of governance with sustainability as the ultimate goal, there are many challenges to deal with. The current increased economic interest in natural resources implies intensified use. This applies both to the European continent's East and West (Angelstam et al. 2011a). However, there are also large differences among landscapes in different countries and regions, which can be used as a natural experiment in social-ecological systems. In the East, countries with transition economies (Myant and Drahokoupil 2010) share several challenges regarding the reformation of their natural resource use, governance, and management as a part of the transition process from planned to market economy (Holopainen et al. 2006; Nysten-Haarala 2009). The West countries are challenged with landscape restoration for biodiversity conservation (e.g., Angelstam et al. 2011b) and human well-being (MEA 2005), especially in the light of the increasing demands of natural resources (Andersson et al. 2012). In addition, in both East and West, there is also a desire to secure livelihoods and human well-being in rural areas (O'Brien and Patsiorkovsky 2006).

There are two objectives of this suite of forewords. First, the research group Forest-Landscape-Society summarizes the research program (2005-2012) behind this special issue of AMBIO, and the group's development process to participate in transdisciplinary research aiming at knowledge production and learning to support the development toward sustainable landscapes (see Haines-Young 2000; Antrop 2006). Second, a group of stakeholders at multiple levels provide their views on the philosophy of knowledge production and learning toward transdisciplinary research presented in this issue.

\section{SUMMARIZING A RESEARCH GROUP'S JOURNEY 2005-2012}

Using a research methodology with case studies in multiple landscapes along distinct gradients in ecological and social systems across the European continent, from the Russian Federation in the East, via Eastern and Central Europe, to the West (e.g., Best 2009; Angelstam et al. 2011a), our aim is to produce novel knowledge and encourage learning for 
sustainable development and sustainability in social-ecological systems (Angelstam et al. 2013a). The vision is thus sustainable landscapes. To apply the "landscape laboratory" design (e.g., Kohler 2002) the "Forest-Landscape-Society" research group at the Swedish University of Agricultural Sciences' School for Forest Management received grants during the periods 2005-2007 and 2008-2012 from the Marcus and Amalia Wallenberg Foundation for the project "Connecting forests, people and markets in Europe's East and West: adaptive governance and assessment of economy, environment, and society at multiple scales and levels." Specifically, the aim of the project was to encourage the triple skills of (1) understanding the needs of landscapes' stakeholders in different cultural contexts, (2) producing relevant knowledge, and (3) communicating it at different levels of society.

Realizing these ambitions requires time. We began in 2005 with the aim to develop our group's ability to apply transdisciplinary research. This collaborative approach can be defined as problem solving that integrates researchers from multiple disciplines, and practitioners from different sectors at multiple governance levels. To understand bridges and barriers to implementing the vision of sustainable landscapes in Europe's East and West, the project was based on collaboration with nonacademic actors and stakeholders at multiple levels, including communicators in media, and with organizations involved in applied research, development, and education.

This special issue of AMBIO with 11 original articles illustrates this research journey (Table 1). We first present a systematic framework in seven steps based on multiple landscapes as case studies, collaboration among academic and nonacademic actors and stakeholders, as well as communication with and dissemination to society at large (I). Next, to make effective use of multiple landscapes, or social-ecological systems, as replicated case studies by careful sampling in gradients that represent variation in biophysical, anthropogenic, and intangible dimensions of landscapes, we highlight the opportunity of bridging the different schools of landscape research in geography (II). Using the Bergslagen region in south-central Sweden as an example, we show the role of landscape history for the sustainability state of contemporary ecological and social systems (III). As an example of the fourth step, mapping stakeholders, use and non-use values, products and land use, we use a large forest management unit in Sweden and one in the Russian Federation to analyze how sustained yield forestry is defined and implemented (IV). To illustrate the importance of institutions, policies, and governance systems, we assess to what extent UNESCO's Biosphere Reserve concept and its core functions are captured in national legislations in Ukraine and Sweden, and show how different political cultures have developed different implementation approaches (V). In a block of three articles, we then illustrate the opportunities and challenges of deriving indicators and measurable variables for ecological (VI), economical (VII), as well as social and cultural (VIII) sustainability dimensions. In a block of two articles, we illustrate the need for assessment or evaluation of sustainability and sustainable development processes by combining knowledge about policies, rules, and norms on the one hand, and the state and trends in ecological systems (IX), and adaptive governance, knowledge production, and learning in social systems $(\mathrm{X})$ on the other. Finally, together with a group of researchers in different phases of learning the practice of transdisciplinary research, we analyze the barriers and bridges to integrative knowledge production and collaborative learning for problem solving (XI).

Apart from publishing the research articles in peer-review journals, including this special issue of AMBIO, we have established productive collaboration with stakeholders from private, public, and civil sectors at multiple levels in Europe's East and West. Our collaboration with stakeholders has resulted in the creation of the NGO Sustainable Bergslagen in Sweden-an emerging partnership working toward sustainable regional development (Axelsson et al. 2013b). Funding from different organizations (the Swedish Ministry of Environment, the European Union, the Swedish International Development Agency and others) supports our efforts to develop networking and neighborhood collaboration among researchers and practitioners toward sustainable landscapes in the Barents and Baltic Sea Regions. To disseminate the results from our research, we have developed education material about sustainable forest landscape management in Europe's East and West for students at forestry universities. Finally, to secure communication with and dissemination to policy-makers, practitioners, and the general public, we have developed a network of researchers, journalists, and communicators in Europe's East and West, and a common communication platform (the web site http://www.euroscapes.org will be officially launched in spring 2013). The research team has also developed contacts with media in Sweden, Russia, and Ukraine.

\section{STAKEHOLDER PERSPECTIVES AT MULTIPLE LEVELS}

\section{Lennart Myhrman: Local and Regional Rural Development}

In Bergslagen where I was born, live, and work, people have for centuries been dependent on the use of the surrounding forest landscape and its natural resources. As long as there was no competition between different ways to use this natural capital there were no conflicts. But when Finns, encouraged by the Swedish government, colonized the sparsely populated wilderness and began to use upland forests for slash and burn cultivation, local hunters and fishermen felt displaced. Peasants from the surrounding plains also claimed the right to use trees for house building and other types of products needed for 
Table 1 Structure of the 11 articles in AMBIO 2013:2

\begin{tabular}{llll}
\hline & Description & Article & References \\
\hline Overview & Seven-step approach & I & Angelstam et al. (2013a) \\
Step 1 & Identify a suite of landscapes as case studies & II & Angelstam et al. (2013b) \\
Step 2 & Study the landscape history & III & Angelstam et al. (2013c) \\
Step 3 & Map stakeholders, use and non-use values, products, and land use & IV & Elbakidze et al. (2013a) \\
Step 4 & Analyze institutions, policies, and governance system & V & Elbakidze et al. (2013b) \\
Step 5 & Measure ecological, economic, social, and cultural sustainability & VI & Richnau et al. (2013) \\
& & VII & Elbakidze et al. (2013c) \\
Step 6 & & VIII & Axelsson et al. (2013a) \\
& Assess sustainability dimensions and governance & IX & Angelstam et al. (2013d) \\
Step 7 & & X & Axelsson et al. (2013b) \\
\hline
\end{tabular}

everyday life. Conflicts among different users of the forest landscape have since always been present, even if the stakeholders and the issues change.

Handling of conflicts among different parties involves the development of mutual understanding of perspectives and needs. There is a need to combine each party's knowledge in a collaborative learning process and to develop experiencebased learning among local, regional, national, and global level stakeholders and initiatives aiming for sustainable development toward sustainability. This would support the creation of a more holistic approach to handle natural resource management. A prerequisite for this process is to map and learn about local stakeholder's interests and values. Such mapping improves understanding of possible goals of sustainable development, thus it could be distinguished according to the different parties, economic, ecological, and social premises. I see this special issue of AMBIO as an important step toward a greater understanding of the processes of sustainable development and sustainable natural resource use.

\section{Alexandr Mariev: Russian Federal Forestry Agency}

Russia's forests make up nearly a quarter of Earth's forest cover. Characterized by high natural and historic diversity, these forests form a strategic renewable resource. Today, in the Russian Federation the societal demand regarding the quality of forest management has increased. Numerous scientific conferences, public discussions in media, public hearings have highlighted that there is an urgent need to develop national forest policy based on collaboration among multiple stakeholders. The main directions of the national forest policy are (1) preservation of forests and increase of forest cover, (2) development of sustainable forest management, (3) creation of an effective forest economy, and (4) a good environment for human life and well-being.

Sustainable forest management is essential for economic and social development. The main request from the forest industry is to adapt forest legislation, including rights of forest users, to historic, economic and social conditions of forest landscapes and regions. To improve the economic performance of forestry, the forest cover should be maintained in landscapes. Special attention is required in the sparsely forested regions, where the creation of protective forests is often needed.

The Russian Federal Forestry Agency is also committed to the development of forestry in combination with agriculture. Such an integrated approach will create conditions for the revival of rural and forest villages, provide jobs and give opportunities for rural development. We are also working on creating opportunities for active public involvement in forest management, especially by local populations. Thus, there is a need to support public hearing and include public expertise of forest management, especially related to forest use and lease.

It is important to learn about experiences of implementing sustainable forest management in countries and regions with different natural, historical, and societal contexts. This issue of AMBIO clearly shows the need to consider both forest ecosystems and society, and their integration in landscapes.

\section{Tatiana Tyopenko: Barents Region Collaboration}

Natural resources and new transport routes have strengthened the Barents Region's strategic significance to Europe. The Barents Region is also known for its clean nature, extensive forest areas, rich natural resources, and the unique culture of its indigenous peoples. All these make the region attractive for investors. Promotion of responsible and sustainable economic activity, taking into account environmental issues, is vital to the region's prosperity. Nobody can remain indifferent to the beauty of Europe's last large intact forest landscapes located in northwestern Russia. Simultaneously, unique natural landscapes have for centuries been a key part of the lifestyle of the indigenous people of the Barents Region. Sustainable development requires a well-informed and balanced approach 
to planned action. This is only possible with the participation of all stakeholders, including government, business, and civil society. However, such a process is very complex. There is neither always a common understanding of problems, nor among different experts. Today, many municipalities lack well-educated professionals, and are thus not able to make appropriate and timely decisions needed for sustainable development.

There is thus need for new know-how, including experiences from other countries. I see a huge potential for the development of neighborhood collaboration based on the experiences of transdisciplinary research presented in this issue of AMBIO. This includes collaborative learning and collaboration, which has been initiated between municipalities in Sweden and the Republic of Komi with the aim to learn from each other, to develop comprehensive plans and to steer the development in their respective territories toward sustainability.

\section{Niels Elers Koch: International Union of Forest Research Organizations (IUFRO)}

Started in 1892 as a small network of forest research institutions, IUFRO is today a global network for forest research and higher learning, representing about 15000 scientists in more than 120 countries. Over the years, IUFRO has transformed from a network of natural scientists to one addressing the whole range of ecological, economic, and social aspects of forests and trees. The representation of social sciences in the network has significantly expanded and today-among others-includes aspects such as forest policy and governance, traditional knowledge, human health, and recreation.

Knowledge production and learning for sustainable landscapes involving forest and tree resources is central to IUFRO's work. To address current policy aims related to sustainable landscapes in a holistic and multi-disciplinary way, IUFRO arranges about 70 annual meetings around the world. Many of these are organized jointly by several scientific disciplines. IUFRO is a member of the Global Partnership of Forest Landscape Restoration, uniting more than 100 organizations toward the promotion of restoring important landscapes for the benefit of society.

Learning for sustainable landscapes also requires adequate dissemination of scientific knowledge to stakeholders and society at large. Over the past decade IUFRO has therefore made science communication and science-policy interactions a priority. To this end, IUFRO informs global policy processes, promotes science-policy interactions through cooperation with regional policy platforms, and supports capacity building of scientists on best practices in science communication and science-policy interactions. The excellent research presented in this issue of AMBIO is in line with IUFRO's dual approach on interdisciplinary research and science-society interaction. Beyond doubt, more on this is needed for the benefit of both forest landscapes and people.

Acknowledgments We express our sincere thanks for the courage of Marcus and Amalia Wallenberg Foundation to support our approach to knowledge production and learning toward sustainable forest landscapes, and to Jan-Erik Hällgren, the former dean of the Faculty of Forest Sciences at the Swedish University of Agricultural Sciences, for invaluable support. This special issue of AMBIO with 11 original articles illustrates our research journey, and constitutes the final project report. With this funding as a backbone, we also acknowledge important contributions to the research presented in this issue from the Swedish Research Council for Environment, Agricultural Sciences and Spatial Planning (FORMAS) and the Swedish Foundation for Strategic Environmental Research (MISTRA), the Swedish Institute, and for collaboration with stakeholders, EU InterReg, the Swedish Environmental Protection Agency, Sveaskog, Mälarenergi, Region Dalarna and the Swedish Ministry of the Environment. Special and sincere thanks to all stakeholders at multiple levels in Europe's East and West for their keen participation in knowledge production and learning processes. We also would like to express our sincere appreciation for the meticulous work carried out by the 39 reviewers of the 11 papers in this issue, Pablo Garrido for his keen secretary function, and the guest editors Audrey Mayers at the Michigan Technical University and Arkady Tishkov at the Russian Academy of Sciences. Finally, thanks to a new strong research environment grant (2012-2016) from FORMAS we will continue applying our approach to producing knowledge and enhance collaboration and learning for sustainable landscapes in Europe's East and West. The focus will be the diagnosis of ecological and social systems in terms of the provisioning, regulating, supporting and cultural ecosystem services, and the benefits that these provide.

Open Access This article is distributed under the terms of the Creative Commons Attribution License which permits any use, distribution, and reproduction in any medium, provided the original author(s) and the source are credited.

\section{REFERENCES}

Andersson, K., P. Angelstam, M. Elbakidze, R. Axelsson, and E. Degerman. 2012. Green infrastructures and intensive forestry: Need and opportunity for spatial planning in a Swedish ruralurban gradient. Scandinavian Journal of Forest Research. doi: 10.1080/02827581.2012.723740.

Angelstam, P., R. Axelsson, M. Elbakidze, L. Laestadius, M. Lazdinis, M. Nordberg, I. Pătru-Stupariu, and M. Smith. 2011a. Knowledge production and learning for sustainable forest management: European regions as a time machine. Forestry 84: 581-596.

Angelstam, P., K. Andersson, R. Axelsson, M. Elbakidze, B.-G. Jonsson, and J.-M. Roberge. 2011b. Protecting forest areas for biodiversity in Sweden 1991-2010: Policy implementation process and outcomes on the ground. Silva Fennica 45: 1111-1133.

Angelstam, P., M. Elbakidze, R. Axelsson, M. Dixelius, and J. Törnblom. 2013a. Knowledge production and learning for sustainable landscapes: Seven steps using social-ecological systems as laboratories. AMBIO. doi:10.1007/s13280-012-0367-1.

Angelstam, P., M. Grodzynskyi, K. Andersson, R. Axelsson, M. Elbakidze, A. Khoroshev, I. Kruhlov, and V. Naumov. 2013b. Measurement, collaborative learning and research for sustainable use of ecosystem services: Landscape concepts and Europe as laboratory. AMBIO. doi:10.1007/s13280-012-0368-0.

Angelstam, P., K. Andersson, M. Isacson, D.V. Gavrilov, R. Axelsson, M. Bäckström, E. Degerman, M. Elbakidze et al. 2013c. 
Learning about the history of landscape use for the future: Consequences for ecological and social systems in Swedish Bergslagen. AMBIO. doi:10.1007/s13280-012-0369-z.

Angelstam, P., J.-M. Roberge, R. Axelsson, M. Elbakidze, K.-O. Bergman, A. Dahlberg, E. Degerman, S. Eggers, et al. 2013d. Evidence-based knowledge versus negotiated indicators for assessment of ecological sustainability: The Swedish Forest Stewardship Council standard as a case study. AMBIO. doi: 10.1007/s13280-012-0377-z.

Angelstam, P., K. Andersson, M. Annerstedt, R. Axelsson, M. Elbakidze, P. Garrido, P. Grahn, I. Jönsson et al. 2013e. Solving problems in social-ecological systems: Definition, practice and barriers of transdisciplinary research. AMBIO. doi:10.1007/ s13280-012-0372-4.

Antrop, M. 2006. Sustainable landscapes: Contradiction, fiction or utopia? Landscape and Urban Planning 75: 187-197.

Axelsson, R., P. Angelstam, E. Degerman, S. Teitelbaum, K. Andersson, M. Elbakidze, and M.K. Drotz. 2013a. Social and cultural sustainability: Criteria, indicators, verifier variables for measurement and maps for visualization to support planning. AMBIO. doi:10.1007/s13280-012-0376-0.

Axelsson, R., P. Angelstam, L. Myhrman, S. Sädbom, M. Ivarsson, M. Elbakidze, K. Andersson, P. Cupa, et al. 2013b. Evaluation of multi-level social learning for sustainable landscapes: Perspective of a development initiative in Bergslagen, Sweden. AMBIO. doi:10.1007/s13280-012-0378-y.

Best, H. 2009. History matters: Dimensions and determinants of national identities among European populations and elites. Europe-Asia Studies 61: 921-941.

Elbakidze, M., K. Andersson, P. Angelstam, G.W. Armstrong, R. Axelsson, F. Doyon, M. Hermansson, J. Jacobsson, et al. 2013a. Sustained yield forestry in Sweden and Russia: How does it correspond to sustainable forest management policy? AMBIO. doi:10.1007/s13280-012-0370-6.

Elbakidze, M., T. Hahn, V. Mauerhofer, P. Angelstam, and R. Axelsson. 2013b. Legal framework for biosphere reserves as learning sites for sustainable development: A comparative analysis of Ukraine and Sweden. AMBIO. doi:10.1007/s13280-012-0373-3.

Elbakidze, M., P. Angelstam, N. Sobolev, E. Degerman, K. Andersson, R. Axelsson, O. Höjer, and S. Wennberg. 2013c. Protected area as an indicator of ecological sustainability? A century of development in Europe's boreal forest. AMBIO. doi:10.1007/ s13280-012-0375-1.

Haines-Young, R. 2000. Sustainable development and sustainable landscapes: Defining a new paradigm for landscape ecology. Fennia 178: 7-14.

Holopainen, P., P. Ollonqvist, and J. Viitanen. 2006. Factors affecting investments in Northwest Russian forest sector and industry. Working Papers of the Finnish Forest Research Institute 32: 1-49.

Kohler, R.E. 2002. Landscapes and labscapes. Chicago: The University of Chicago Press.

MEA (Millenium Ecosystem Assessment). 2005. Ecosystems and human well-being: Synthesis. Washington, DC: Island Press.

Myant, M., and J. Drahokoupil. 2010. Transition economies: Political economy in Russia, Eastern Europe, and Central Asia. Hoboken, NJ: Wiley.

Norgaard, R.B. 2010. Ecosystem services: From eye-opening metaphor to complexity blinder. Ecological Economics 69: 1219-1227.

Nysten-Haarala, S. (ed.). 2009. The changing governance of renewable natural resources in Northwest Russia. Aldershot: Ashgate.

O'Brien, D.J., and V.V. Patsiorkovsky. 2006. Measuring social and economic change in rural Russia: Surveys from 1991-2003. Lakham, MD: Lexington Books.

Richnau, G., P. Angelstam, S. Valasiuk, L. Zahvoyska, R. Axelsson, M. Elbakidze, J. Farley, I. Jönsson, et al. 2013. Multifaceted value profiles of forest owner categories in South Sweden: The
River Helge å catchment as a case study. AMBIO. doi:10.1007/ s13280-012-0374-2.

\section{AUTHOR BIOGRAPHIES}

Per Angelstam $(\bowtie)$ is a professor in forest and natural resource management. He is interested in development and sustainability, and focuses on empirical studies of social-ecological systems with different landscape histories and governance systems.

Address: Faculty of Forest Sciences, School for Forest Management, Swedish University of Agricultural Sciences, P.O. Box 43, 73091 Skinnskatteberg, Sweden.

e-mail: per.angelstam@slu.se

Marine Elbakidze is an associate professor in geography. Her research interests include landscape ecology, forest management, landscape governance, and integrated spatial planning for sustainable development and sustainability.

Address: Faculty of Forest Sciences, School for Forest Management, Swedish University of Agricultural Sciences, P.O. Box 43, 73091 Skinnskatteberg, Sweden.

e-mail: marine.elbakidze@slu.se

Robert Axelsson is a researcher with a $\mathrm{PhD}$ in forest management. $\mathrm{He}$ is interested in research that supports the collaborative social learning process of sustainable development. His aim is to learn how to facilitate transdisciplinary research.

Address: Faculty of Forest Sciences, School for Forest Management, Swedish University of Agricultural Sciences, P.O. Box 43, 73921 Skinnskatteberg, Sweden.

e-mail: robert.axelsson@slu.se

Niels Elers Koch is a professor, director of the Danish Centre for Forest, Landscape, and Planning at University of Copenhagen, and president of the International Union of Forest Research Organizations (IUFRO).

Address: Forest \& Landscape Denmark, University of Copenhagen, Rolighedsvej 23, 1958 Frederiksberg C, Denmark.

e-mail: nek@life.ku.dk

Tatiana I. Tyupenko is responsible for international collaboration at the Ministry of Natural Resources and Environmental Protection Republic of Komi, and a Member of the Regional Working Group on Environment of the Barents Region.

Address: Ministry of Natural Resources and Environmental Protection of the Komi Republic, 108a Internatsionalnaya Street, Syktyvkar, Komi Republic, Russian Federation.

e-mail: t.i.tyupenko@minpr.rkomi.ru

Alexandr N. Mariev heads the Russian Federal Forestry Agency's department for forest use and regeneration.

Address: Russian Federal Forestry Service, Pyatnitskaya Street 59/19, 115184 Moscow, Russian Federation.

e-mail: les.mariev@gmail.com

Lennart Myhrman is a local champion who is engaged in rural development at multiple levels. He is the chairman of the Foundation Säfsen Forests, chairman of LEADER Bergslagen, and an elected representative of Swedish Leader Initiatives in Mälardalen and Bergslagen.

Address: Gamla Nåsvägen 10A, 77010 Fredriksberg, Sweden. Address: LEADER Bergslagen, Box 101, 73922 Skinnskatteberg, Sweden.

e-mail: lennart.myrman@telia.com 